\title{
GONOCOCCAL ARTHRITIS
}

By Mr. DAVID LEES, D.S.O., F.R.C.S.Ed.

\section{Discussion}

Colonel HARrison said : I should like to congratulate you on the very clear exposition of this subject. You said that you would touch only on controversial points, but I have heard nothing with which I would disagree. It has always been a source of wonder to me that our colleagues in other branches of medicine are often so blind to the implication of an arthritis and omit that examination of the genital passages which would often disclose the nature of the process. Like most of us here, I could relate many instances of patients having suffered for years and become permanently crippled through gonococcal arthritis, which could have been brought to an end very quickly, without deformity, if the medical man in charge of the case had only instituted an examination of the urogenital passages at an early stage.

With regard to diathermy, my impression is that Cumberbatch and Robinson have always emphasised the great importance of applying this method of treatment to the focus of infection rather than to the joints. I doubt if diathermy acts by killing the gonococci, but it is reasonable to suppose that it may attenuate them, or it may give rise to an auto-inoculation, but probably the chief reason for its beneficial effect is that it promotes drainage of the infected focus.

With regard to routes of administration of vaccine, I should like to suggest that the intradermal is worthy of a more extended trial. At St. Thomas's Hospital we have been treating a number of cases with a vaccine made on the principles evolved by Dimond at the Royal Herbert Hospital, Woolwich. The vaccine is injected intradermally into a number of sites, giving approximately $0 \cdot I$ to $0 \cdot 2$ c.c. into each, and its effect is really remarkable. The local reaction occurs very quickly, there is usually slight rise of temperature on the day of the injection and a very definite increase in joint symptoms; this is 


\section{GONOCOCCAL ARTHRITIS}

followed in approximately twenty-four hours by considerable improvement in the condition of the joints. I am not sure whether the effect is due to a specific action of the gonococcal vaccine, or is non-specific, but it is certainly good.

I should like to give credit to the author of the use of arsenobenzene preparations in keratodermia blennorrhagica ; we owe it to Sir Robert Bolam. During the War, at Rochester Row we had a case of gonococcal arthritis with generalised keratodermia which was going downhill after we had done everything we could think of. I mentioned the case to Colonel Bolam, who suggested our giving an arsenobenzene preparation. This was done, and the patient made a rapid recovery.

Dr. DAvid NABARro wished to associate himself with Colonel Harrison in offering congratulations to the President in regard to this address, which the speaker had enjoyed very much; it had been extremely instructive to all the members.

He had not much to add to the discussion, as his own work was chiefly among children, and the President had only had two cases among children, who had ophthalmia neonatorum, and this latter condition was not treated at Great Ormond Street Children's Hospital.

In 250 cases which he, Dr. Nabarro, had had of vulvovaginitis in twelve years, there had not been a single case of arthritis. There had been one case of teno-synovitis of the ankle, but no conjunctivitis or iritis had occurred in association. Probably that was because the organism did not get into the blood stream and produce metastases, or it might be that the joint tissues in the child were not so vulnerable as in the adult. He remembered one case, which occurred under Mr. Waugh twelve years ago, in which a joint was full of pus, and in which the speaker found the gonococcus in that pus. That was the only case of gonococcal arthritis he had seen in nineteen years at Great Ormond Street, so it must be a very rare condition indeed.

He was interested in the President's remarks about mobilisation of the affected joint, i.e., allowing the joint to be moved as much and as early as possible, as he, Dr. Nabarro, had been in the habit of doing the same thing in cases of Clutton's joints in syphilis. Cases of the latter had come to him on a splint, and he had suggested it be 


\section{BRITISH JOURNAL OF VENEREAL DISEASES}

removed, because directly one started injections the joint seemed to cause no trouble, and it was better to move the joint than to put it into splinting.

He could not add anything useful to the discussion, as gonococcal arthritis did not come into his purview.

Mr. J. F. PEART said that he, likewise, had enjoyed the President's paper, which he had found to be very instructive. He did not know whether the reader included vasotomy in the operations dealt with, as he, Mr. Peart, did not arrive in time to hear the whole paper. There was not a more rational procedure, he thought, than vasotomy, as the centre for dissemination of the poison was in those tissues, viz., the seminal vesicles and prostatic ducts, and by attacking them direct one was acting on the right principles in treatment.

His experience on this subject had been limited, but it was useful. Not long ago he was asked by a doctor in the north of London to see a patient who had developed acute gonorrhœal arthritis of one knee-joint three weeks after becoming infected with gonorrhœa. When seen by the speaker he still had his arthritis and was running a temperature. He advised the man to have vasotomy done, and that was carried out. In a fortnight it was well and the arthritis had cleared up, and there had been no recurrence to date. That one result seemed to show it was an efficacious procedure. Whether it would prove successful in every case was another matter. He would imagine there were very many chronic cases in which the operation would be exceedingly useful.

MR. V. E. LLOYD joined with other speakers in appreciation of the President's excellent address. He was pleased to hear Mr. Lees lay so much stress on the importance of mobilisation of the gonococcal joint; it was a mistake to immobilise them for long periods. $\mathrm{He}$ had seen gonococcal joints which had been in splints four and five months on end, the result usually being an ankylosed joint. The President stated that he removed the splints as soon as the pain had ceased; and the speaker carried out the same principle, though in a different way: he splinted the joint at night, and kept it off in the daytime, sandbags were then employed and the use of the joint encouraged. Usually, if a patient had had a good night he did not mind some pain the next day.

He would join issue with the President concerning the 


\section{GONOCOCCAL ARTHRITIS}

spurs which appeared in the calcaneus region. He, the speaker, had seen twelve of these cases, and he was convinced that in many cases the spur was of gonococcal origin. Most of the cases were in males, and were associated with chronic gonococcal prostatitis, vesiculitis and arthritis. Many attempts had been made to recover the gonococcus, either locally in the os calcis, or in the blood stream, but there was failure in practically every case. One worker, however, reported a positive result from the spur itself. Possibly these spurs were some type of toxic effect, rather than a metastatic result. These spurs were associated with infection in the plantar ligament or fascia, and frequently there was a bursa under the heel, over the spur. He believed Fournier was the first to draw attention to their association with the arthritis of gonorrhœa.

He would be glad to know the President's opinion as to the rôle of the secondary infections in the urethra in relation to the cause, or the continuation, of the arthritis. He had always felt that they were of considerable importance, because he saw many bad joints in people giving a history of gonorrhœa many years previously, and although there was sepsis somewhere in the genitourinary tract; attempts to find the gonococcus usually failed. Secondary infections, however, were nearly always found in these cases. That there was some connection was confirmed by the results of vaccine therapy. In many one secured better results from using vaccines made from the secondary organisms than from the gonococcus solely.

DR. MoRna RaWlins expressed her agreement with everything the President had said in his paper. At Guy's she saw a woman with acute gonorrhoal arthritis of the hip. At first the limb was immobilised, but this was followed by the right knee becoming involved, and she had hæmaturia badly. She recovered, and was now well. She was now keen on not fixing joints in that way, and it was her practice to follow out Mr. Lloyd's practice of only splinting at night.

Dr. Hardy Kingston asked whether the President was satisfied that keratodermia was a gonorrhœal manifestation. Was it not, rather, a variety of psoriasis? The latter view received support from the fact that the keratodermia yielded quickly to arsenical medication.

DR. MCLACHLAN said that the prostate was one of the 


\section{BRITISH JOURNAL OF VENEREAL DISEASES}

foci which were frequently associated with cases of rheumatism other than primarily gonococcal. He had examined the prostatic secretions in a series of cases of subacute rheumatism, and had found streptococci and coliform organisms, and in those cases treatment by autogenous vaccines helped enormously.

With regard to splintage in acute gonorrhœal joint infections, for a knee condition he put on a back splint, but unless the foot was splinted adequately, there was great danger of foot-drop and loss of power in the anterior muscles of the leg. The best results were obtained by means of a plaster-of-Paris case and controlling the joints above and below. In the last few cases he had so treated, the pain was relieved in twenty-four hours or less. One should keep a joint immobilised, keeping an eye on it all the time, until the swelling decreased, when movement could be started. The plaster case prevented the joint being tampered with till due time.

He did not think sufficient attention was paid in these cases to massage and re-education of the muscles. Treatment must be persisted in for a long time in order to get back full strength in the muscles and restore the full use of the limb.

$\mathrm{He}$ wondered whether any members had noticed in these cases a true neuritis : he had recently seen a case where was a definite neuritis of the anterior tibial nerve, associated with affections of the knee and ankle.

DR. F. DOBLE remarked that, in Uganda, joint affections were more common than epididymitis in gonorrhœea, probably because of the acuteness of the disease, which, when he was there from I9I3 to I9I7, was greater than he had seen in England. He saw forty cases among white men. In Italy, during the War, joints which were affected were put in plaster of Paris for periods of from three to six months by the Italian doctors. He had seen cases for which operation had been arranged, and he intervened and suggested that instead of amputation, prostatic massage and semi-fixation of the joint should be carried out for a time, and that had obviated operation. The tendency amongst surgeons was to say: "Let us get the joint right first, then we will have medications." The complement fixation test was of the utmost help in deciding whether the joints infections were gonococcal in origin or not. 